\title{
Hydatid Cyst of Parotid Gland: An Unusual Case Diagnosed by Fine Needle Aspiration Biopsy
}

\author{
Tuba KARA ${ }^{1}$, Rabia BOZDOĞAN ARPACI ${ }^{1}$, Yusuf VAYISOĞLU², Ebru SERINSÖZ1', Didar GÜRSOY', \\ Anıl ÖZGÜR ${ }^{3}$, Demir APAYDIN³ ${ }^{3}$ Cengiz ÖZCAN²
}

Departments of ${ }^{1}$ Pathology, ${ }^{2}$ Otorhinolaryngology and ${ }^{3}$ Radiology, Mersin University, Faculty of Medicine, MERSIN, TURKEY

\begin{abstract}
Hydatid disease is a zoonotic disease caused by the parasite Echinococcus granulosus. This infection frequently infects the liver and the lung and even in endemic regions rarely occurs in the head and neck region. This is also true for the parotid gland. The diagnosis relies on imaging techniques and the medical history. Another method that is helpful in the diagnosis is serological tests. Fine-needle aspiration biopsy is usually not recommended due to the potential risk of anaphylactic shock or spreading of daughter cysts. The preferred treatment method of hydatid cysts in the salivary gland is surgical excision. We introduce a rare case of hydatid cyst in the parotid gland diagnosed preoperatively by fine-needle aspiration biopsy and discuss the differential diagnosis.
\end{abstract}

Key Words: Diagnosis, Fine-needle biopsy, Echinococcosis, Parotid gland

\section{INTRODUCTION}

Echinococcus granulosus (E. granulosus) causes hydatid disease, which is a momentous infection and still common in Mediterranean countries (1). The liver is the most frequently $(65 \%)$ involved organ, but the infection also shows a multi-organ involvement, particularly in the lung, spleen, kidneys, heart, bone, and central nervous system (2). In the life cycle of the parasite, dogs (and other canines) are the definitive hosts and a variety of organisms such as sheep, goats, horses, and humans are the intermediate hosts. Intermediate hosts ingest eggs by the faecal-oral route and the embryos are released in the small intestine and then enter the portal circulation and travel to visceral capillary beds, usually the liver or the lung, and develop into cystic lesions. However, several eggs may pass through the liver to the systemic circulation and heart and localize in many organs and areas such as the orbit, heart, and bladder $(3,4)$.

Salivary gland lesions have traditionally been investigated by fine-needle aspiration biopsy (FNAB). This is a simple technique that is well-tolerated by patients and hence can be performed repeatedly if required (5). However this method has been used as a diagnostic procedure for hydatid cyst based on a case series involving different organs and many single case reports (6).

The head and neck region and especially the parotid gland is an infrequent localisation for hydatid cyst, even in geographical areas where echinococcosis is endemic. Such

(Turk Patoloji Derg 2017, 33:171-174)

Received : 05.07.2013 Accepted : 25.07.2013 involvement was first reported in 1947 by Martini and there have only been a few case reports in the English literature ever since (7-9). It is generally not considered in the differential diagnosis of parotid lesions preoperatively as it is a rare entity in this localisation. Herein, we present hydatid disease localised in the parotid gland and discuss the preoperative diagnosis with FNAB and the differential diagnosis.

\section{CASE REPORT}

A 54-year-old woman presented at the otorhinolaryngology clinic with a complaint of rapidly growing mass in the left parotid gland for the last month that was accompanied by mild pain. There was no record of fever or weight loss within this time and nothing else remarkable in the history. Physical examination revealed a $3 \times 2 \mathrm{~cm}$ irregular semimobile mass in the left parotid gland. Ultrasonographic examination of the neck region showed an unechoic well-defined, circular mass with acoustic enhancement in the left parotid gland. FNAB was performed under ultrasonographic control. Serous fluid was aspirated from the mass, indicating that the mass was cystic and most likely benign. The first FNAB of the lesion yielded no definitive diagnosis. Psammomalike bodies were seen in the cytology specimen and renewed aspiration was recommended for the final diagnosis (Figure 1). The second aspiration showed scolices, hooklets, inflammatory cells and histiocytes (Figure 2,3), and was reported as hydatid cyst. The re-examination of the first aspiration revealed that the psammoma like bodies were the protoscolex of the parasite.

Correspondence: Tuba KARA

Mersin Üniversitesi Tip Fakültesi, Patoloji Anabilim Dalı

Zeytinlibahçe Caddesi, 33079, Akdeniz, MERSINN, TURKEY

E-mail: karabacaktuba@hotmail.com Phone: +90 5322450349 
Computed tomography (CT) scan of the thorax, ultrasonography (USG) of the abdomen, and urologic examination were performed to rule out the contingency of dissemination into the viscera, and revealed no involvement of extracervical sites. The clinician therefore decided to remove the mass. During surgery, the cystic lesion has replaced most of the inferior part of the left parotid gland, and frozen-section studies confirmed the diagnosis of hydatidosis (Figure 4). Superficial parotidectomy was therefore performed. Light microscopic examination with clear evidence of hydatid scolices and laminated membrane verified the preliminary diagnosis of hydatidosis (Figure 5). Albendazole therapy was administered for 2 months after the operation with liver enzyme and blood count followup. The patient was asymptomatic with no recurrence of the hydatid cyst at the 1-year follow-up.

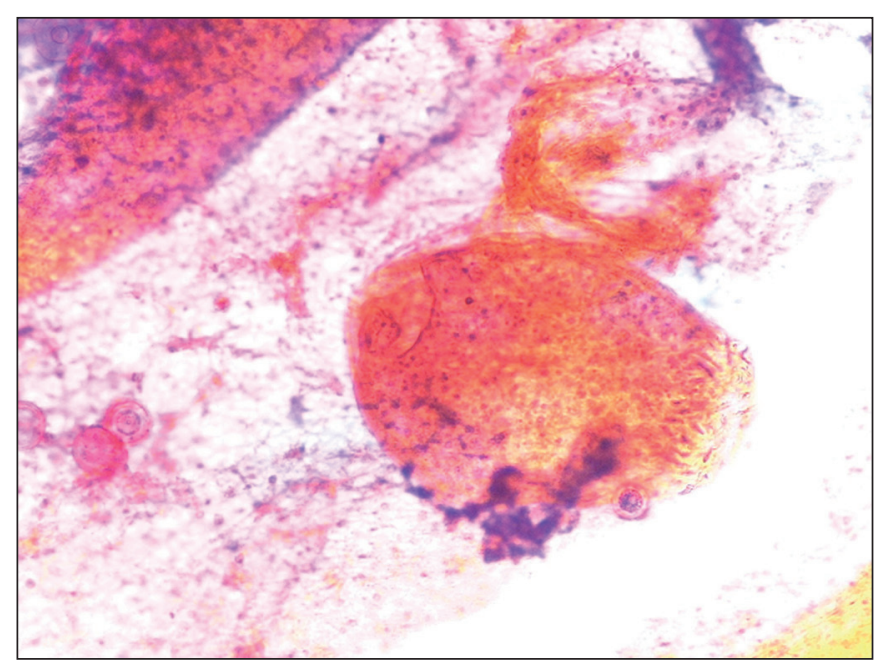

Figure 2: Scolices (Papanicolaou; x100).

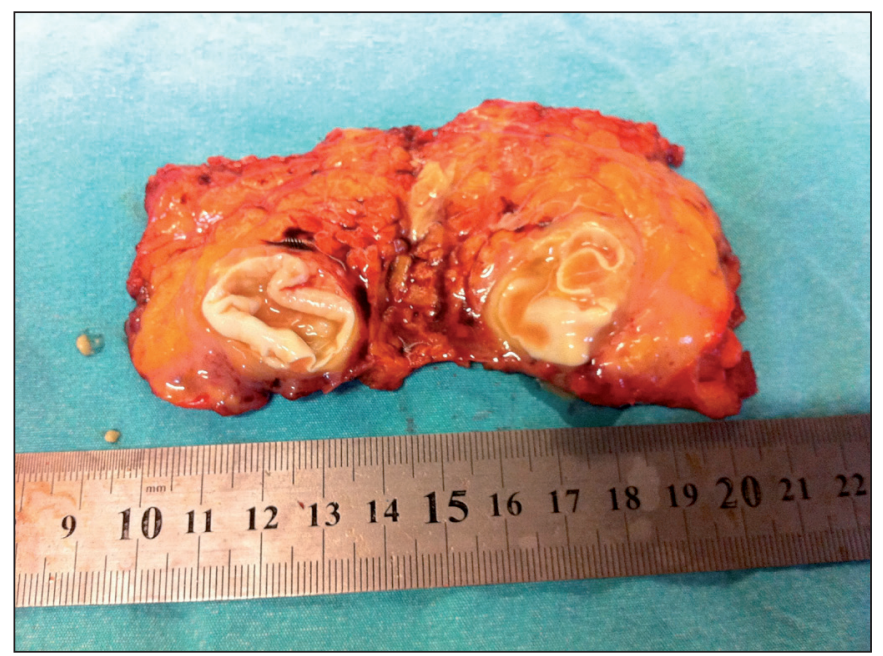

Figure 4: Typical laminated membrane of the cyst replaced most of the inferior part of the parotid gland.

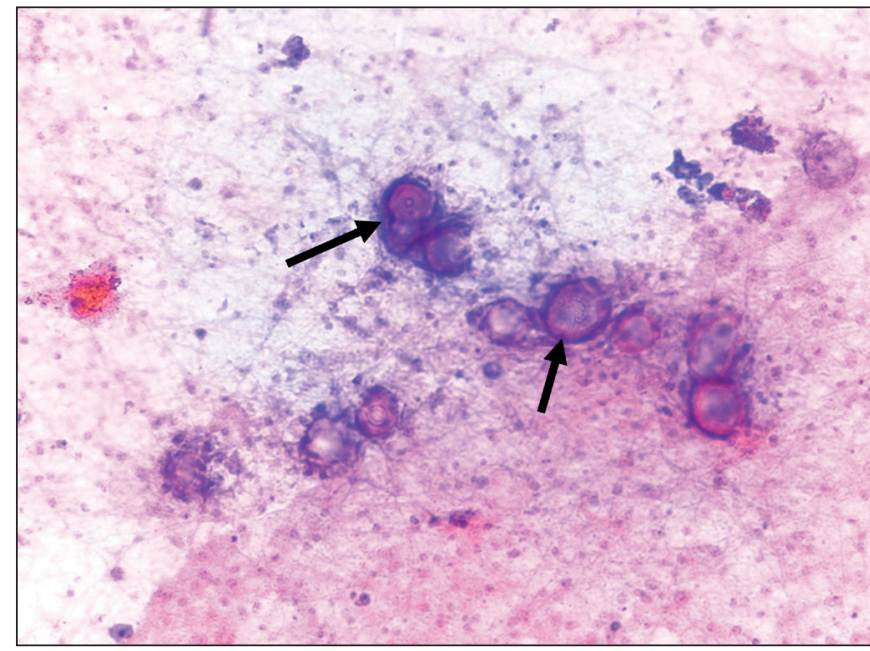

Figure 1: Psammoma like bodies, arrows (Papanicolaou; x100).

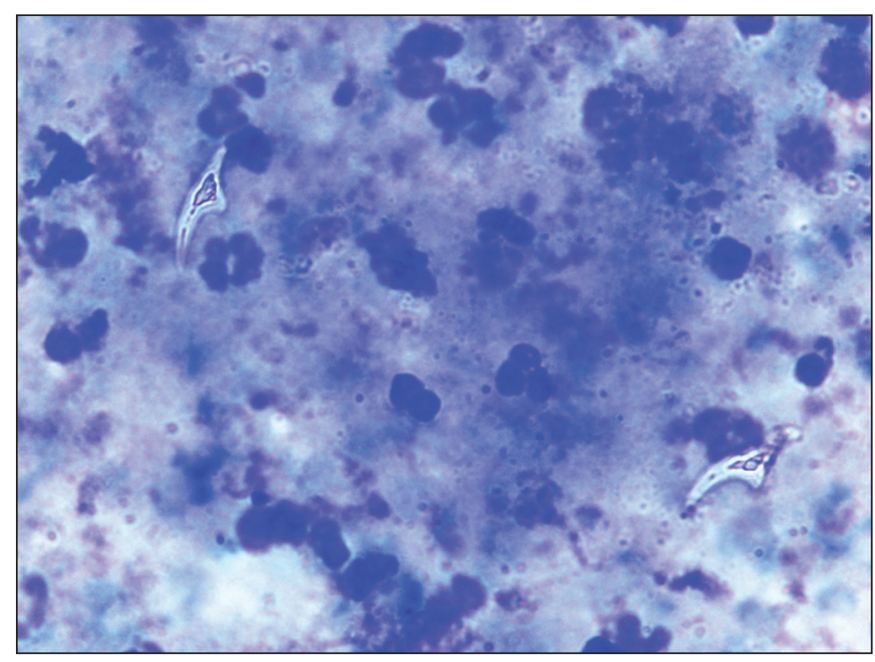

Figure 3: Hooklets between inflammatory cells and histiocytes (MGG; x400).

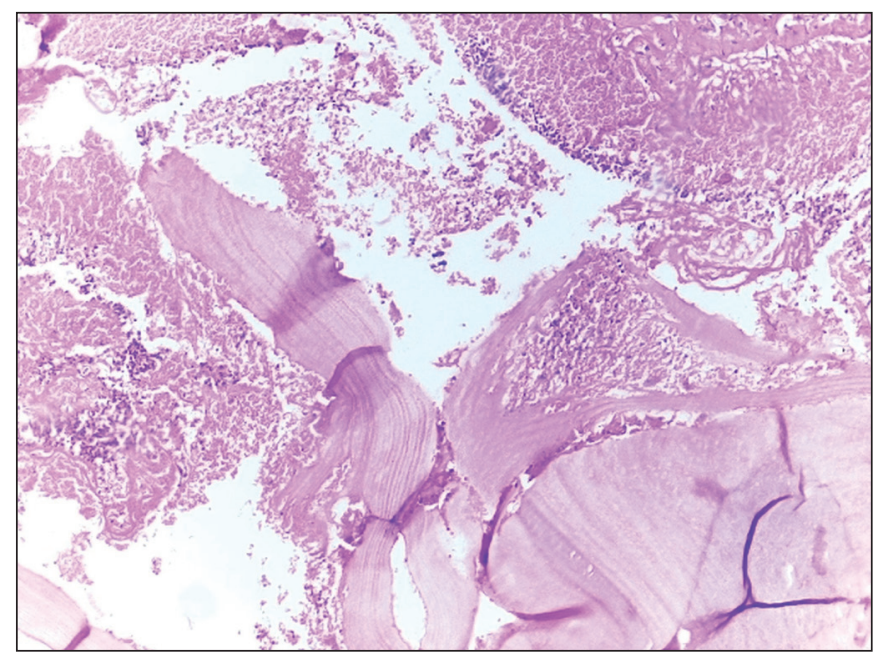

Figure 5: Laminated membrane between inflammatory cells (H\&E; x200). 


\section{DISCUSSION}

Echinococcosis or hydatid disease is a parasitic infestation caused by larvae of the tapeworm E. granulosus. Both animals and humans are involved as an accidental host, do not play a role in the biological cycle, and are usually infected by handling an infected dog (9). Hydatid cysts are common in the liver and lung, whereas head and neck region involvement is a rare finding. There are only a small number of case reports in the literature (9-13).

Although most hydatid cysts are slow-growing and asymptomatic, the mass effect of the cyst on the infected organ may lead to emergence of clinical symptoms. Knowledge of the involved area in the patient may enable the consideration of hydatid cyst in the differential diagnosis but preoperative diagnosis may not be possible unless radiological findings are present or suspicious for hydatid cyst (10). Hydatid disease should be considered in the differential diagnosis of congenital and acquired cystic lesions of the parotid gland in endemic areas. Dermoid and epidermoid cysts may also be present in the parotid gland. The first branchial cleft cysts and rarely cystic hygromas can also be seen in these glands. Some benign and malignant tumors of parotid gland may also present as cystic masses (9). Imaging methods such as USG, CT, and magnetic resonance imaging (MRI) have an important role in the diagnosis of hydatid disease. USG is the preferred method for the demonstration of pathognomonic criteria such as the hydatid sands besides floating membranes, daughter cysts, and also vesicles in completely cystic lesions (14). MRI is the most useful imaging technique for the diagnosis of cases that do not have characteristic USG features of hydatid cyst (15).

Serological tests, such as agglutination methods, immunoelectrophoresis, skin tests, as well as enzyme-linked immunosorbent assay (ELISA) have low diagnostic sensitivity and specificity but are the first line laboratory tests used to confirm the diagnosis (16). These tests are more important during follow-up (17). Imaging methods are more sensitive than serology, and a USG or CT examination showing the characteristic features of hydatid cyst would suggest the diagnosis in case of negative serological results (16). A through systemic examination must be done to rule out the involvement of other organs, and especially the liver and lungs, when hydatid disease is found (2).

The use of FNAB in the diagnosis of hydatid disease is still controversial. In general, it is not recommended due to the potential risk of precipitating acute anaphylaxis or spreading daughter cysts (18). This risk seems to have attracted great attention in the past but there are also a large number of articles indicating that diagnosing hydatid disease cytologically is a safe procedure without complications (19). Only one case of cervical hydatid cyst that developed an anaphylactic reaction during the FNAB procedure has been reported so far. Although there are so few reported cases of allergy, adequate emergency precautions should always be taken to overcome these situations (20). Clinicians should be aware of the possibility of the cervical localisation of the hydatid cyst and should avoid biopsy procedures before surgery due to the minimal but dangerous risks. No anaphylactic reaction was observed in our case and this is the first case of hydatid cyst located in the parotid gland diagnosed by FNAB to the best of our knowledge.

Hydatid cyst uncommonly occurs in the head and neck region but it should be considered in the differential diagnosis of cervical masses, especially in endemic areas. Imaging methods such as USG, CT, and MRI play an important role in the diagnosis of hydatid disease. However, the initial diagnosis was made by FNAB in our case. Although the technique helps make the diagnosis before surgery, the risk of causing an anaphylactic reaction should always be kept in mind.

\section{REFERENCES}

1. Akhan O, Dincer A, Gokoz A, Sayek I, Havlioglu S, Abbasoglu O, Eryılmaz M, Besim A, Baris I. Percutaneous treatment of abdominal hydatid cysts with hypertonic saline and alcohol: An experimental study in sheep. Invest Radiol. 1993;28:121-7.

2. Turgut S, Ensari S, Katirci H, Celikkanat S. Rare otolaryngologic presentation of hydatid cyst. Otolaryngol Head Neck Surg. 1997;117:418-21.

3. Eroglu A, Atabekoglu S, Kocaoglu H. Primary hydatid cyst of the neck. Eur Arch Otorhinolaryngol. 1999;256:202-4.

4. Yuksel M, Demirpolat G, Sever A, Bakaris S, Bulbuloglu E, Elmas N. Hydatid disease involving some rare locations in the body: A pictorial essay. Korean J Radiol. 2007;8:531-40.

5. Stewart CJ, MacKenzie K, McGarry GW, Mowat A. Fine-needle aspiration cytology of salivary gland: A review of 341 cases. Diagn Cytopathol. 2000; 22:139-46.

6. Das DK, El-Sharawy M, Ayyash EH, Al-Enezi NA, Iqbal JR, Madda JP. Primary hydatid cyst of the supraspinatus muscle: Complete removal of the germinal layer and cytodiagnosis by fine-needle aspiration. Diagn Cytopathol. 2014;42:268-72.

7. Emamy H, Asadian A. Unusual presentation of hydatid disease. Am J Surg. 1976;132:403-5.

8. Karahatay S, Akcam T, Kocaoglu M, Tosun F, Gunhan O. A rare cause of parotid swelling: Primary hydatid cyst. Auris Nasus Larynx. 2006; 33(2):227-9.

9. Darabi M, Varedi P, Mohebi AR, Mahmoodi S, Varedi P, Nabavizadeh SA, Erfan A, Ostadali Makhmalbaf A, Saedi D, Saadat Mostafavi SR, Mousavi SM. Hydatid cyst of the parotid gland. Oral Maxillofac Surg. 2009;13:33-5. 
10. Akal M, Kara M. Primary hydatid cyst of the posterior cervical triangle. J Laryngol Otol. 2002;116:153-5.

11. Karaman E, Yilmaz M, Ada M, Yilmaz RS, Isildak H. Unusual location of primary hydatid cyst: Soft tissue mass in the parapharyngeal region. Dysphagia. 2011;26:75-7.

12. Baglam T, Karatas E, Durucu C, Sirikci A, Kara F, Kanlikama M. Primary hydatid cyst of the infratemporal fossa. J Craniofac Surg. 2009; 20:1200-1.

13. Iynen I, Sogut O, Guldur ME, Kose R, Kaya H, Bozkus F. Primary hydatid cyst: An unusual cause of a mass in the supraclavicular region of the neck. J Clin Med Res. 2011;3:52-4.

14. Polat P, Kantarci M, Alper F, Suma S, Koruyucu MB, Okur A. Hydatid disease from head to toe. Radiographics. 2003;23:47594.

15. Alouini Mekki R, Mhiri Souei M, Allani M, Bahri M, Arifa N, Jemni Gharbi H, Kochtali H, Tlili Graiess K. Hydatid cyst of soft tissues: MR imaging findings (report of three cases). J Radiol. $2005 ; 86: 421-5$.
16. Tekin M, Osma U, Yaldız M, Topcu I. Preauricular hydatid cyst: An unusual location for echinoccosis. Eur Arch Otorhinolaryngol. 2004; 261:87-9.

17. Bouckaert MM, Raubenheimer EJ, Jacobs FJ. Maxillofacial hydatid cysts. Oral Surg Oral Med Oral Pathol Oral Radiol Endod. 2000; 89:338-42.

18. Sennaroglu L, Nerci M, Turan E, Sungur A. Infratemporal hydatid cyst: Unusual location of echinococcosis. J Laryngol Otol. 1994; 108:601-3.

19. Das DK, Bhambhani S, Pant CS. Ultrasound guided fine-needle aspiration cytology: Diagnosis of hydatid disease of the abdomen and thorax. Diagn Cytopathol. 1995; 12:173-6.

20. Knoch H, Helbig M, Schirren J, Tasman AJ. Cystic spaceoccupying lesion of the neck soft tissues: Cave echinococcosis. HNO. 1999;47(3):188-91. 